\title{
ENTOMOLOGIA HELLENICA
}

Vol 1 (1983)

\section{VOLUME 1 (1983) \\ ENTOMOLOGIA \\ HELLENICA}

PUBLISHED BY THE HELLENIC ENTOMOLOGICAL SOCIETY
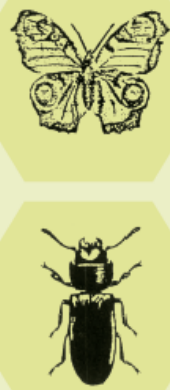
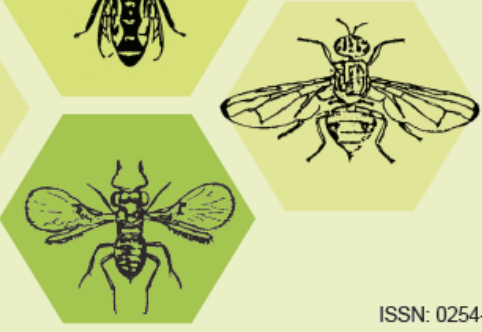

Inhibition of larval growth of Dacus oleae by topical application of streptomycin to olives

M.E. Tzanakakis, D.A. Prophetou, G.N. Vassiliou, J.J. Papadopoulos

doi: $\underline{10.12681 / \text { eh.13896 }}$

Copyright @ 2017, M.E. Tzanakakis, D.A. Prophetou, G.N. Vassiliou, J.J. Papadopoulos

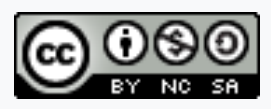

This work is licensed under a Creative Commons Attribution-NonCommercialShareAlike 4.0.

To cite this article:

Tzanakakis M., Prophetou, D., Vassiliou, G., \& Papadopoulos, J. (1983). Inhibition of larval growth of Dacus oleae by topical application of streptomycin to olives. ENTOMOLOGIA HELLENICA, 1, 65-70. https://doi.org/10.12681/eh.13896 


\title{
Inhibition of Larval Growth of Dacus oleae by Topical Application of Streptomycin to Olives ${ }^{1}$
}

\author{
M.E. TZANAKAKIS, D.A. PROPHETOU, G.N. VASSILIOU \\ and J.J. PAPADOPOULOS
}

\author{
Laboratory of Applied Zoology and Parasitology \\ University of Thessaloniki, Greece
}

\begin{abstract}
Olives of four varieties were oviposited by females of Dacus oleae (Gmelin) (Diptera: Tephritidae). One to four hours or one day later, a $5 \mu \mathrm{l}$ drop of streptomycin sulphate solution in tap water was applied to the oviposition hole. If applied 1-4 hours after oviposition, concentrations of $0.1,0.3$, or $1 \%$ were equally effective, inhibiting larval growth in over $85 \%$ of the olive fruits. If applied one day later, the $0.1 \%$ concentration was less effective, while the 0.3 and $1 \%$ ones retained their high effectiveness. With 2 $\mu \mathrm{l}$ drops, inhibition was not significantly lower than with $5 \mu \mathrm{l}$ drops.

The addition of $0.05 \%$ or $0.5 \%$ Agral 90 , a spreader-wetter, had an activating effect, causing a substantial and significant increase of the percent inhibition.
\end{abstract}

\section{Introduction}

The olive fruit fly, Dacus oleae (Gmelin) (Diptera: Tephritidae), lays its eggs singly in the mesocarp of green or ripe olives and the larva bores a gallery in it, while feeding. When the fruit is green, such as during summer and early autumn, the larva needs the presence of symbiotic bacteria in its digestive tract in order to utilize the parts of the mesocarp it ingests. If the adult mother is treated with streptomycin, the presence or the activity of symbiotic bacteria is adversely affected to a degree that does not allow the larvae to grow in freshly picked green olives (Hagen 1966). It is also known that when the olives are either black-ripe or green but cold-stored for relatively long periods, larvae can grow in them even if their mothers had been treated with streptomycin. The riper the olives the shorter the period of cold storage necessary to render the olive

Received for publication December 23, 1983. mesocarp suitable for such, presumably aposymbiotic, larvae to grow and develop (Fytizas and Tzanakakis 1966 a, b). Work by our group showed that the growth of $D$. oleae larvae is inhibited also if the olive fruits were treated with streptomycin a few days before, to one day after oviposition (Tzanakakis and Stavrinides 1973, Tzanakakis et al. 1975). The treatment consisted of momentary immersion of the olives in $1 \%$ or $5 \%$ solutions of streptomycin sulphate in tap water with a spreaderwetter, or of longer immersion of up to 2 hours without the spreader-wetter, or of topically applying a $5 \dot{\mu}$ l drop over each oviposition hole.

The present work aimed at determining, by topical application, the minimal concentration of streptomycin necessary to effectively inhibit larval growth, when applied at three different periods of time after oviposition, as well as the necessity for a spreader-wetter. It aims at understanding the conditions under which streptomycin is effective against the symbiotic bacteria of Dacus eleae, and is part of our effort to try to control this insect using a symbioticide 
rather than an insecticide.

\section{Materials and Methods}

The work was carried out in 1974, 1982, and 1983 . In 1974, the mother flies were $F_{1}$ of individuals field-collected as pupae in Halkidiki of northern Greece. They were reared in the laboratory on olives. Care was taken to have an equal representation of mother flies of a particular origin ovipositing in the olives of each experiment. In 1982, the flies were 11 th generation descendants of flies field-collected also in Halkidiki and reared ever since on olives, while in 1983 they were $\mathrm{F}_{1}$ of flies field-collected in a neighboring area. The flies were maintained in standard $30 \times 30 \times 30 \mathrm{~cm}$ cages and had access to water and a diet favoring high fecundity. Unless specified otherwise, the procedure was as described by Tzanakakis et al.(1975).

The olives were of the following four varieties: Megaritiki (MEG) having fruits of a medium size, approximately 600 fruits $/ \mathrm{Kg}$, an atypical variety resembling Megaritiki (MEG-LIKE) with fruits of medium size, approximately 400 fruits $/ \mathrm{Kg}$, Koutsourelia $(\mathrm{KO})$ having 700 fruits $/ \mathrm{Kg}$, and Konservolia (KONSE) also known as Amphisis, a large fruit variety having 150 fruits $/ \mathrm{Kg}$. The MEG-LIKE olives were from trees near the city of Thessaloniki, while those of the other three varieties from groves of coastal Halkidiki. They were picked green in August and September and cold stored at $+^{\circ} \quad 6^{\circ} \mathrm{C}$ in the dark in perforated plastic bags, until used for the tests. The dates of picking and periods of cold storage are given in the figures. On the day of oviposition the olives were placed in the fly cages long enough for one or a few eggs to be laid in each fruit. Only fruits with one oviposition hole were used in the tests.

The treatment consisted of placing a $5 \mu \mathrm{l}$ or $2 \mu \mathrm{l}$ drop of a solution of streptomycin sulphate in tap water, with or without Agral 90, a spreader-wetter, over the oviposition hole. Topical application was done $1-4$ hours, 1 day, and 2 days at $24^{\circ}-26^{\circ} \mathrm{C}$. after oviposition. The treated olives were left individually on a rack for approximately 1 hour to allow the drops to evaporate and/or penetrate the oviposition holes. Then, they were placed in covered cups of hard plastic and maintained at $24^{\circ}-26^{\circ} \mathrm{C}$ for 3 weeks. Such a time was sufficient to allow larvae in untreated fruits to complete their growth and pupate. Larval growth was considered as inhibited in those fruits where no pupae or 3rd instar larvae were found at the end of the 3-week period.

There were 2 replicates of 30 fruits per treatment. Differences were compared at the 0.05 level using the $\mathrm{z}$ criterion. In the discussion that follows, we consider "effective" the concentrations that inhibited larval growth in at least $85 \%$ of the fruits, and also those concentrations that did not differ significantly from them, even if they were little below $85 \%$. In the text that follows, streptomycin refers to streptomycin sulphate in tap water, and Agral to Agral 90 . Further details are given in the results section.

\section{Results and discussion}

When streptomycin was applied to the fruits 2 days after oviposition, without the spreaderwetter, the percent of fruits with larval growth inhibited was low, not differing significantly from the untreated control even in the highest concentration tested. This occurred with all three olive varieties tested in 1974 and 1982 . Therefore, those data were not included in the figures. A similarly low percent of inhibition was observed when streptomycin was applied 2 or 3 days after oviposition, when olives were treated by brief immersion (Tzanakakis and Stavrinides 1973). When streptomycin was applied a few hours or 1 day after oviposition, the percent inhibition varied with the concentration of streptomycin from high to low levels (Figure 1 and 2). The following can be seen:

\section{Effective streptomycin concentrations}

When MEG olives picked in mid August 1974 and cold stored for 26 days were topically treated a few hours after oviposition, the inhibition of larval growth reached approximately $87 \%$ with either $0.1,0.3$, or $1 \%$ streptomycin (Fig. 1). When treated 1 day after oviposition, the inhibition with 0.3 and $1 \%$ was of the same order of magnitude and significantly not different from olives treated a few hours after oviposition. With $0.1 \%$, however, it was less. This holds also for the KO variety.

In $\mathrm{KO}$ olives picked in early September 1974, cold stored for 37 days and treated a few hours after oviposition, the inhibition was at all concentrations higher, though not significantly, than in MEG olives. In KO olives treated 1 day after oviposition, inhibition was slightly higher than in MEG with $0.1 \%$ and slightly lower with 0.3 and $1 \%$. Differences between the two varieties were again not significant. In KO olives picked in late September 1974 and cold stored for 71 days, inhibition was at all concentrations and at both times of treatment lower, but not significantly, than in olives of 


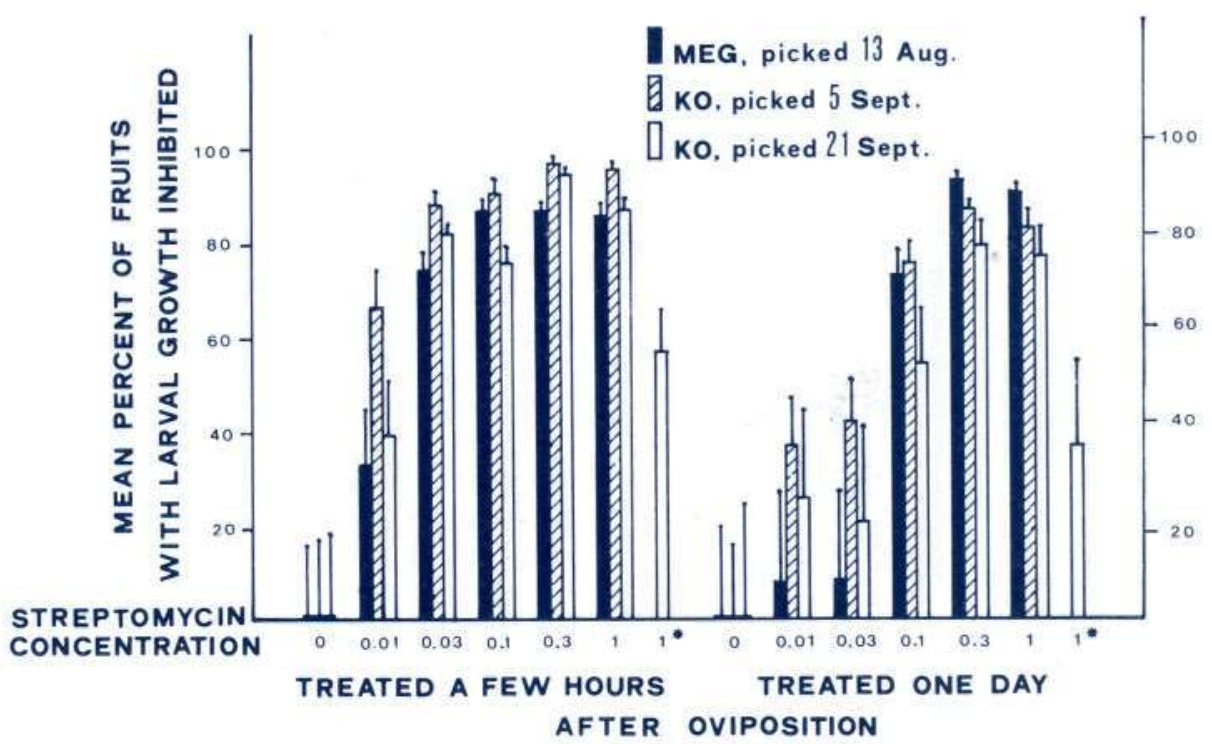

FIG. 1. Inhibition of larval growth of Dacus oleae in olives of the variety MEG picked on 13.VIII.1974 in coastal Halkidiki and cold stored for 26 days, and of the variety KO picked in the same grove on 5 and 21.IX.1974 and cold stored for 37 and 71 days, respectively. The olives were treated topically with $5 \mu \mathrm{l}$ drops of streptomycin sulphate solutions. The height of each column shows the corrected inhibition and the top of the vertical line above each column the observed inhibition. The columns with an asterisk concern olives treated by immersion with $0.05 \%$ Agral 90 added to the solution.

the same variety picked earlier and cold stored for a shorter period of time. This reduced percent of inhibition should be expected on the basis of previous work which showed that the riper the untreated olives and the longer their cold storage the lower the percent inhibition of growth of larvae whose adult parents had received streptomycin in their diet (Fytizas and Tzanakakis $1966 \mathrm{a}, \mathrm{b})$. When these KO olives were treated by brief immersion in $1 \%$ streptomycin plus $0.05 \%$ Agral, inhibition was considerably and significantly lower than when they were treated topically with a solution of the same concentration without Agral. Therefore, topical application seems to be more effective than fruit immertion as applied so far by our group.

Inhibition with MEG olives was in most cases less, though not significantly, than with $\mathrm{KO}$ olives. Differences between varieties should be expected, since the fruit must have differed in degree of maturity at any given date they were picked, and possibly also in the rate their mesocarp changes per unit of time of cold storage.
Based on significant differences between concentrations which gave $85 \%$ or higher corrected inhibition, the minimal effective concentrations of streptomycin by topical application of $5 \mu \mathrm{l}$ drops were as follows: for olives treated a few hours after oviposition $0.03 \%$ with the MEG and $\mathrm{KO}$ varieties, and for olives treated 1 day after oviposition $0.3 \%$ with MEG and $0.1 \%$ with $\mathrm{KO}$ picked in early September but not in late September. With KONSE olives picked in late September of another year (1982) and cold stored for 38 days (Fig. 2), $0.3 \%$ was effective if applied a few hours but not if applied 1 day after oviposition. However, with KONSE olives, inhibition at $0.03 \%$ although differing significantly from that with $0.3 \%$ was only little below the adopted $85 \%$ minimum for effectiveness. With MEG-LIKE olives picked in late September 1983 and cold stored for 35 days (Fig. 3), 0.3\% was likewise effective if applied a few hours but not if applied 1 day after oviposition.

In 1982 with KONSE olives and without the addition of Agral to the streptomycin solutions (Fig. 2), inhibition with $2 \mu \mathrm{l}$ drops was at all 


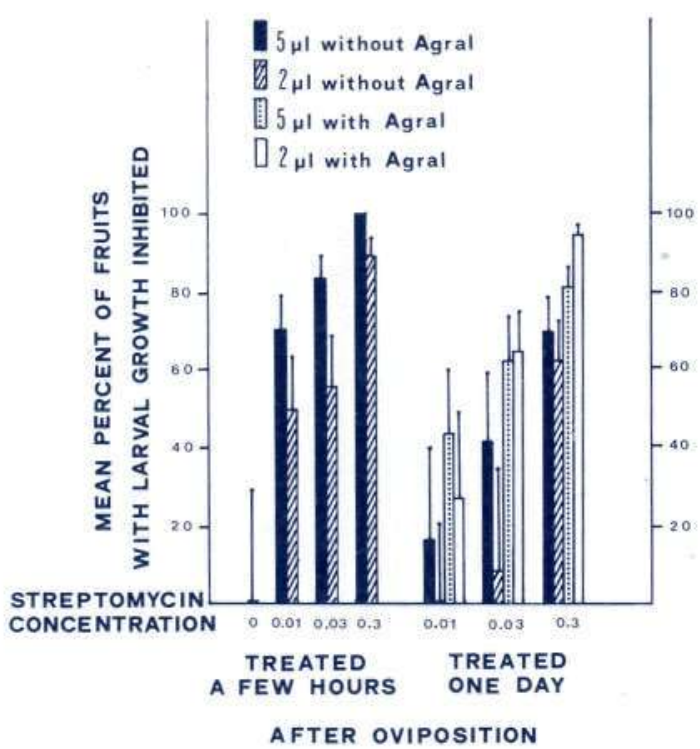

FIG. 2. Inhibition of larval growth of Dacus oleae in olives of the variety KONSE picked on 23.IX.1982, in coastal Halkidiki, cold stored for 38 days, and treated topically with 5 and $2 \mu \mathrm{l}$ drops of streptomycin sulphate solutions with or without $0.05 \%$ Agral 90 . The height of each column shows the corrected inhibition, and the top of the vertical line above each column the observed inhibition.

concentrations lower that with $5 \mu \mathrm{l}$ drops, but not significantly. In 1983, with MEG-LIKE olives too (Fig. 3), differences in inhibition between 2 and $5 \mu \mathrm{l}$ drops were minor and not significant.

\section{The effect of a spreader-wetter}

When $2 \mu \mathrm{l}$ drops of streptomycin solutions were applied topically to KONSE olives 1 day after oviposition, the addition of $0.05 \%$ Agral caused a significant increase of inhibition (Fig. 2). With $5 \mu \mathrm{l}$ drops, which generally gave higher percentages of inhibition, the addition of Agral caused a significant increase of inhibition at the 0.01 but not at the 0.03 and $0.3 \%$ concentrations. Agral was also tried the next year using the MEG-LIKE variety, picked on 29.IX.1983 and cold stored for 35 days before use. Agral was then used at $0.5 \%$ i.e. at a concentration 10 times that of the previous year. In all cases where inhibition without Agral was fairly low, the addition of this spreader-wetter caused a considerable and significant increase of inhibition. This was true whether the sol- utions were applied as 2 or as $5 \mu \mathrm{l}$ drops, 4 or 24 hours after oviposition. When the $0.3 \%$ concentration was applied 4 hours after oviposition, the percent inhibition without Agral exceeded $90 \%$. In such a case a striking increase could not be expected. A similar favorable effect of Agral was noted when the drops were allowed to evaporate with fruits inverted, so that the oviposition holes were facing down. Agral by itself was not inhibitory to larval growth at either 0.5 or $1 \%$.

Agral has been useful for increasing to high levels the inhibition of larval growth of Dacus oleae in olives treated by brief immersion (Tzanakakis and Stavrinides 1973, Tzanakakis et al. 1975). One explanation we proposed for the increased inhibition due to this spreaderwetter was that Agral allows the streptomycin solutions to cover the whole fruit surface, including the oviposition hole. Coverage of the oviposition hole is a requisite for inhibition (Tzanakakis et al. 1975). However, the increase in inhibition when the fruits are treated topically, shows that the activating action of Agral is exerted also in another way, possibly

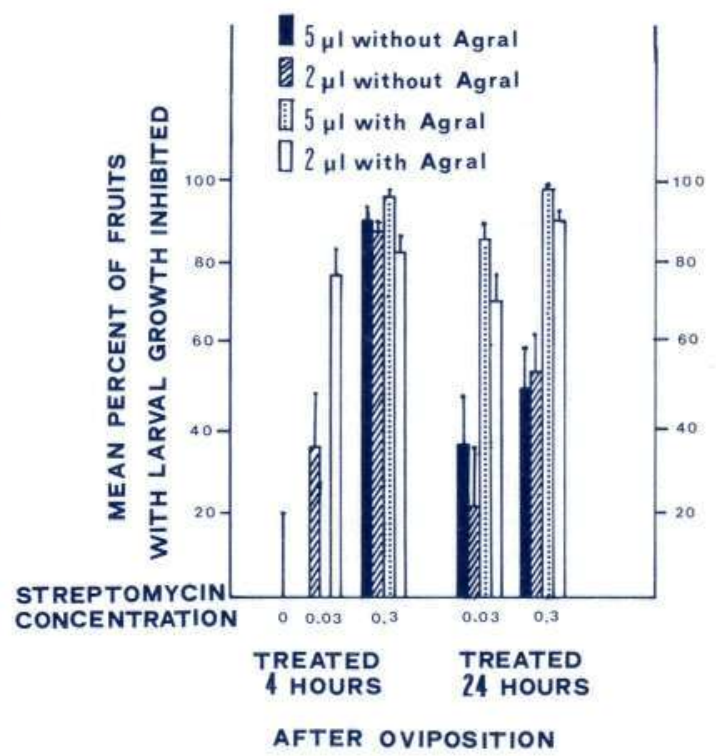

FIG. 3. Inhibition of larval growth of Dacus oleae in olives of the variety MEG-LIKE picked on 29.IX.1983, near Thessaloniki, cold stored for 35 days, and treated topically with 5 and $2 \mu \mathrm{l}$ drops of streptomycin solutions with or without $0.5 \%$ Agral 90 . The height of each column shows the corrected inhibition and the top of the vertical line above each column the observed inhibition. 
improving the penetration of streptomycin solutions inside the oviposition chamber, over the surface of the egg, and/or into the sites of the micropylar area of the egg where the fly's symbiotic bacteria are abundant, as reported by Mazzini and Vita (1981). The matter certainly needs further investigation.

\section{Acknowledgment}

We thank the Parks Department of the City of Thessaloniki for allowing the free collection of olives, Dr. B.I. Katsoyannos for criticizing the manuscript, Mr. C. Kafetzis for technical assistance, and Miss M. Pantzaropoulou for drawing the figures.

\section{References}

Fytizas, E. and M.E. Tzanakakis. 1966a. Développement des larves de Dacus oleae dans des olives, lorsque leurs parents ont reçu la streptomycine, incorporée à leur nourriture. Ann. Epiphyties 17: 53-59.

Fytizas, E. and M.E. Tzanakakis. 1966b. Some effects of streptomycin when added to the adult food on the adults of Dacus oleae and their progeny. Ann. Entomol. Soc. Amer. 59: 269-273.

Hagen, K.S. 1966, Dependence of the olive fly. Dacus oleae, larvae on symbiosis with Pseudomonas savastanoi for the utilization of olive. Nature (Lond.) 209: 423-424.

Mazzini, M. and G. Vita. 1981. Identificazione submicroscopica del mecanismo di trasmissione del batterio simbionte in Dacus oleae (Gmelin) (Diptera, Trypetidae). Redia 64: 277-301.

Tzanakakis, M.E. and A.S. Stavrinides. 1973. Inhibition of development of larvae of the olive fruit fly, Dacus oleae (Diptera: Tephritidae), in olives treated with streptomycin. Ent. exp. \& appl. 16: 39-47.

Tzanakakis, M.E., D.A. Prophetou, M.C. Savopoulou and A.G. Kordelas. 1975. Inhibition of larval growth of Dacus oleae (Diptera: Tephritidae) by streptomycin. I. Effect of duration of olive fruit immersion, temperature, and chemical additives on inhibition; effective site of topical application on oviposited olives. Ent. exp. \& appl. 18: 302-312.

KEY WORDS: Antibiotic effects, Dacus oleae, Insect symbioticides, Larval growth inhibition, Olive fruit fly, Streptomycin effects, Tephritidae growth inhibition, Surface-active substance effects

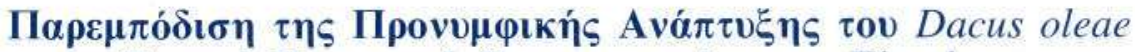

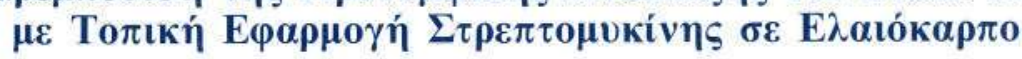

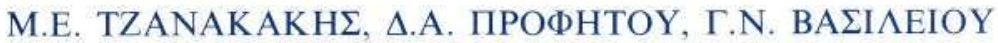 \\ К І I.I. ПАПА $\triangle О П О Y \Lambda O \Sigma$

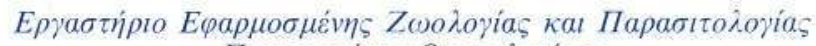

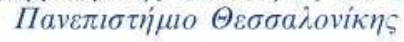

\section{ПЕРІАНЧН}

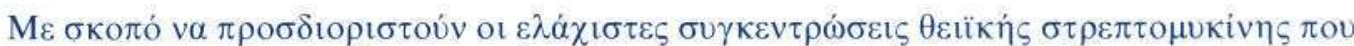

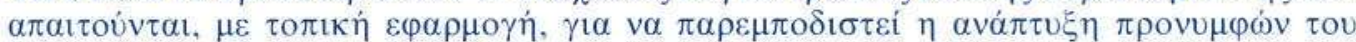

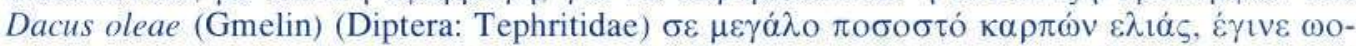

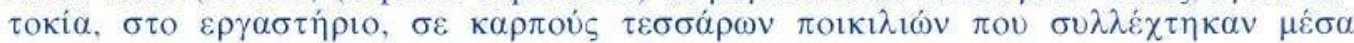

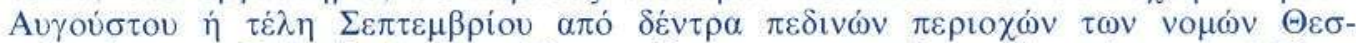

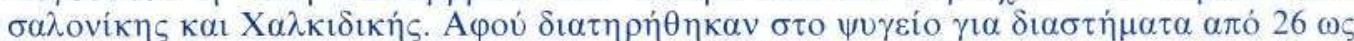

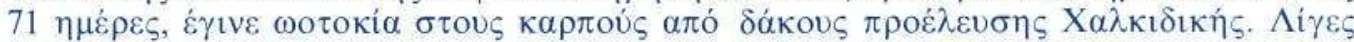

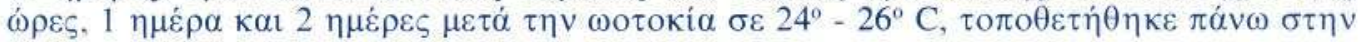




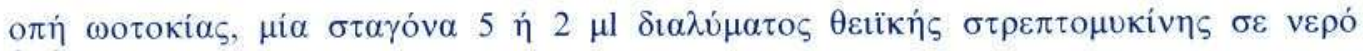
Bpúons.

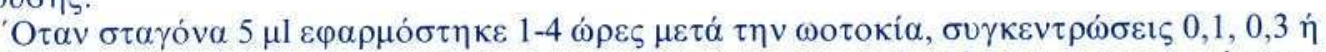

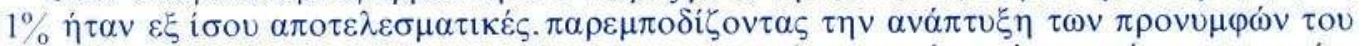

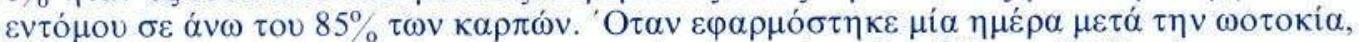

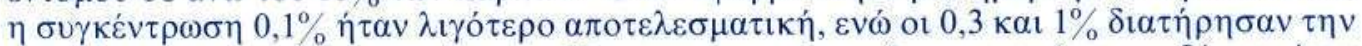

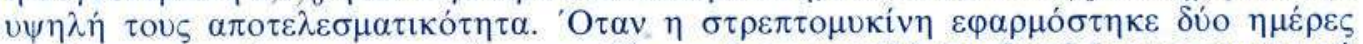

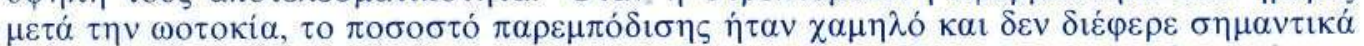

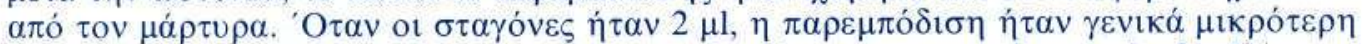

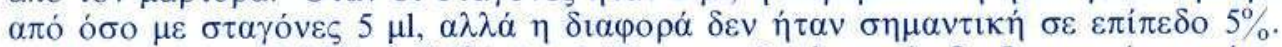

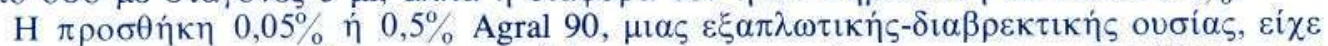

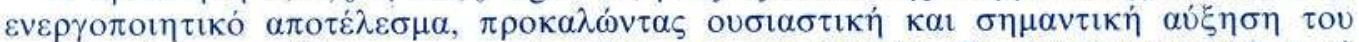

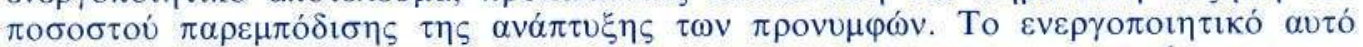

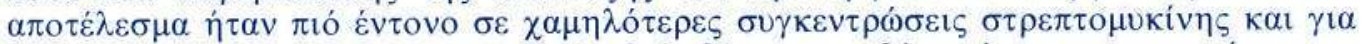

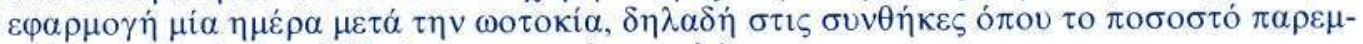

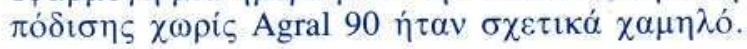

